REGULAR ARTICLE

\title{
LAND DEALS AND SMALL-SCALE INTENSIVE FARMING DECISIONS
}

\author{
Prince NKETIAH (D), Michael AYAMGA (D), Franklin N. MABE (D)
}

\begin{abstract}
Address:
Department of Agricultural and Resource Economics, Faculty of Agribusiness and Communication Sciences University for Development Studies, Nyankpala Campus, Tamale, Ghana

Corresponding Author's e-mail: mfnantui@uds.edu.gh
\end{abstract}

\begin{abstract}
The upsurge of land deals in Northern Ghana is a concern to many stakeholders. In order to reduce the effects of land deals on livelihoods, farmers resort to adopting semi-intensive, intensive or low intensive farming systems. Using a multinomial logit model, this study assessed how land deals influence the decision of a farm household to choose any of the farming regimes. Factors that influence farmers' decision to choose intensive as against semi-intensive methods of farming are farm size, awareness of land grabbing, intension of cultivating part of grabbed land, number of adults, household expenditure, location, remittances and land grabbed investment type. On the other hand, households' engagement in low intensive as compared to semi-intensive methods of farming are influenced by age, fallowing period, education, remittances, and household expenditure. Land deals must be accompanied by efforts to diversify livelihoods of smallholder farmers away from land-based systems. This would require skills training for rural peasant farmers to enable them take up emerging livelihood opportunities. In order to safeguard the interests and livelihood of rural peasants, agricultural investment programmes must make community-investor partnership a key condition for gaining access to government and donor incentives.
\end{abstract}

Keywords: Land deals, semi-intensive, intensive, low intensive system

JEL: R52, R58, H41

\section{INTRODUCTION}

In developing countries, rural farm households derive income from foraging the forests (Wunder et al., 2014). The increasing dependence of rural farm households on land and other land-based resources like forest means that activities that impact on land and forest would have direct implications on rural farm households and their livelihoods. Biodiversity loss in itself has a direct influence on forest-livelihood linkages which are increasingly exposed to risk as human activities continue to diminish habitat for other flora and fauna. An example of risk to biodiversity and forest ecosystems is the increasing demand on land for commercial agricultural purposes (Somorin, 2010). Human activity is affecting the existence and inter-dependence of the environment and mankind, as habitats are continually transformed for agriculture, managed forest or urban development (Polasky et al., 2005).

Farm households make decisions against risk factors towards achieving the best outcomes as they guard against events and incidences that reduce their perceived incomes and/or increase their cost of production. Such undesired events and incidences (i.e. escalating cost of inputs, high climate variability, land loss, etc.) constitute farmers' risk. Onset and persistent land grabbing increase the farmers' likelihood of losing their productive lands.

The risk is much pronounced when rural people are deprived of usufruct rights and access to the benefits of land under customary tenure systems. Hardship on rural households is exacerbated when access to important livelihood assets such as water bodies, wild fruits, herbs, game, timber and economic trees is curtailed. This situation diminishes the livelihood options of rural farm households (Kranjac-Berisavljevic, 2015). Reduced livelihood assets have direct forward linkage to increased migration, diversification and the intensification of farm lands as evident from the livelihood framework developed by Scoones (1998). Land deals by domestic and transnational corporations have been shown to have profound effects on land relations and access to land for smallholders as they contribute to reduced livelihood assets, which in turn have direct effect on livelihood strategies. Many people have become alarmed of the spate and upsurge of land acquisition in developing counties especially in African continent.

Within the framework of Goldstein and Udry (2008), increasing demand for land is a source of risk. A risk that limits usufruct land right holders' ability to fallow land in an optimal manner. There is a risk to the farming system in that gaining access to more land for extended fallowing to regenerate depleted land is limited. Land deals by domestic investors and transnational corporations is a source of risk to smallholder farmers and has a bearing on their livelihood and farming system choices.

There has been outcry against the selling of land by chiefs and other customary authorities in Ghana as land commercialization spreads across the length and breadth of the country over the past three decades (Yaro and Tsikata, 2014). The widespread appropriation of land by chiefs and major clan heads has implications on smallholder inclusive development (Jayne et al., 2014) 
and the ability of households to acquire land to build and develop sustainable livelihood systems around agriculture.

Despite arguments that much of the land grabs in Ghana occur in "so-called open lands," Yaro and Tsikata (2014) argue that grabbed lands include bush lands and common lands, which are the sources of valuable resources which supplement other agrarian livelihood activities and protect the long term survival of smallholder agriculture. Yaro and Tsikata (2014) pointed that there is the risk to the survival of smallholder farming systems thus threatening the livelihood alternatives for smallholders as a result of land acquisition. The effects of land deals on farmer risk perception and response behaviour is the main focus of this study. While there is documented evidence by Kranjac-Berisavljevic (2015) and Schoneveld et al. (2011) on medium and large scale land grabs across Ghana, the study of its impact on farm households as agricultural risk and a livelihood choice decision making remains less explored.

This study explores how land deals in Northern Ghana influence agricultural livelihood choice decisions (intensive, semi intensive and low intensive method of farming). Based on Pressman (2011), a farm household method of farming is intensive if the farm household engages in two or more of the following: mechanized land preparation, use of improved seed, application of chemical fertilizer, use of weedicide and pesticides. Also, he defined semi-intensive farm household as a farm household who engages in two or more of the following: mechanized land preparation, use of improved or local seed, application of partial organic fertilizer as well as chemicals whereas a low intensification farm household is a farm household who engages in two or more of the following: partial or no mechanized land preparation, use local seed, application of no chemical fertilizer and chemicals. Policy makers can rely on the determinants (especially land deals factors) of farmers' livelihood choice decisions in the midst of medium and large scale land acquisitions explored by this study to factor into decisions (intensive, semi intensive and low intensive method of farming) and directions on the dimensions of land grabbing and the overall effect it would have on the agricultural sector of the Ghanaian economy.

The objective of our study was to assess how land deals influence the decision of a farming household to choose any of the farming regimes: intensive, semiintensive or low intensive systems of farming. This will help researchers make actionable policy recommendations for stakeholders to implement so as to minimise the effects of dealing on livelihoods of rural peasant farmers.

\section{DATA AND METHODS}

\section{Description of Study Areas}

The study was conducted in Northern Ghana. Northern Ghana mainly comprises Upper East region, Upper West region, Northern region and some portions of Volta and Brong-Ahafo regions. Its land size covers about $41 \%$ of the total land area of the country, with about $20 \%$ inhabitation of the people of Ghana. The specific districts selected for the study are Gushiegu and Kassena Nankana
East (KNE) of Northern and Upper East regions of Ghana respectively. Data from the Lands Commission of Ghana shows that most of the acquisitions in Northern Ghana occur within the Northern and Upper East Regions. The data further confirms that 21 different parcels of land ranging between 10.12 ha to 24.28 ha have already been acquired and registered in the Kassena Nankana East Municipality in the Upper East Region alone. In the Northern Region, 27 different parcels of land ranging between 20.00 ha to 50.00 ha are also registered in the Gushiegu District. This study takes special interest in these high recording areas within the two regions for a better appreciation of the land grab situation in Northern Ghana.

Kassena Nankana Municipal has been reported by the Ghana Statistical Service (GSS) (2014a) to have 82.7 percent of households engaging in agriculture. In the rural localities, 93.1 percent of households are agricultural households while in the urban localities, 56.8 percent of households are into agriculture. Most households in the Municipality (96.1\%) are involved in crop farming with poultry (chicken) as the dominant animal reared in the municipality. Gushiegu District on the other hand is one of the twenty-six (26) administrative districts of the Northern Region of Ghana. According to Ghana Statistical Service (2014b), about $91.8 \%$ of the households in the district are engaged in agriculture. It is estimated that $96.9 \%$ are agricultural households while in the urban localities, 75.2 percent of households are into agriculture with most of these households (98.0 \%) involving in crop farming (Ghana Statistical Service, 2014b).

\section{Data Collection and Instrumentation}

The basic unit of analysis was the household. This means that data and observations were collected at the household level and the source of the data was primary. Household is defined by the GSS as; individuals and groups who agree to share pooled resources irrespective of the degree of its tangibility in order to earn a living (GSS, 2012). Such people may at most times share the same compound. The study focused on the head of the farm household who is in control of almost all economic resources available to the household for the general upkeep of the entire members of the household. The household head is therefore assumed to be in the best position to offer an account of the various degrees of opportunities, shocks and treats to the entire household. Using a semi-structured questionnaire with closed-ended and open-ended questions, data were gathered from household heads through face-to-face interview.

\section{Sampling Technique}

To effectively achieve the aim of this research, the study grouped the communities under two broad strata (Affected and Non-affected) using stratified random sampling technique. Affected communities are communities with one or more commercialized land parcels acquired within its defined boundaries whilst non-affected communities are communities with no grabbed land parcel within its defined boundaries. Within the affected community, a sub-division was further used to define individual 
respondents as those who lost one or more farm lands to the activities of commercial land acquisitions within the community and those who did not lose any farm land to the activities of commercial land acquisitions within their community. Systematic random sampling was then used to select respondents.

\section{Sample Size Determination}

According to Ghana Statistical Service (2014), the total population of Kassena Nankana East (KNE) and Gushiegu Districts are 107,435 and 110,039 respectively. The census report also shows that Gushiegu District has a total household count of 19,790 as against 11,150 of the KNE Municipal. Furthermore, the report indicated that in the two districts lies the fact that $82.7 \%$ of the households in KNE are engaged in agriculture whilst $91.8 \%$ of the farm households in Gushiegu are engaged in agriculture. The household survey embarked by this study relied on the respective percentage of agricultural household out of the total household count as the sample frame for the determination of appropriate sample size. The mathematical formula adopted for the estimation of the sample size in this study is given as;

$n=\frac{N Z^{*} \times P(1-P)}{e^{2}(N-1)+Z^{*} P(1-P)}$

Where:

$n$ Sample size; $N$ Sample frame; $Z^{*}$ Z-score; $P$ Standard deviation; $e$ Margin of error.

Substituting a $95 \%$ confidence level, standard deviation of 0.5 and a $10 \%$ margin of error to the sample frame of $\mathrm{KNE}$ gives,

$n=\frac{9221 \times 1.96[0.5(0.5)]}{0.1^{2}(9921)+1.96[0.5(0.5)]}=48.75 \approx 49$

Whereas for Gushiegu Districts gives,

$n=\frac{18167 \times 1.96[0.5(0.5)]}{0.1^{2}(18167)+1.96[0.5(0.5)]}=48.87 \approx 49$

Based on the specific interest of this study, it was very necessary to have more respondents. Hence a scale factor of 2 was used to get a sample size of 97.5 and 97.74 from KNE and Gushiegu Districts respectively. Meanwhile, at the end of the data collection, 94 and 108 household heads were interviewed in KNE and Gushiegu Districts respectively.

\section{Multinomial Logit Model: Effects of Land Deals on Farm Livelihood Choice Decisions}

This segment examined factors influencing farm household's livelihood choice decisions (intensive, semi intensive and low intensive method of farming) within affected communities in the study area. The study employed multinomial logit regression analysis in identifying how land deals factors influence farm households' choice of intensive, semi intensive and low intensive method of farming. The variable of interest has three categories which are mutually exclusive and hence the appropriate model is multinomial logistic regression as noted by Greene (2012). Thus, each alternative regime has an associated utility.

According to Greene (2012), the general model for examining the factors influencing a farm households' probability of choosing $j^{\text {th }}$ farm livelihood strate gy for $i^{\text {th }}$ farmer $\left(P_{i j}\right)$ is specified with reference to Equation (2).

$P\left(Y_{i}=j\right)=\frac{\exp \left(x_{i}^{\prime} \beta_{J}\right)}{\sum_{j=1}^{n} \exp \left(x_{i}^{\prime} \beta_{J}\right)}$

Where: $j=1,2,3$ which represent outcomes for intensive, semi-intensive and low intensification; $X$ socioeconomic characteristics of farm household; $\beta$ unknown parameter estimates of explanatory variables; $P$ probability of choosing a livelihood strategy.

Equation (2) specified above is not identified; it is only identified when one of the coefficients is arbitrarily set to zero. This study therefore equates the coefficient of semi-intensive to zero, hence becomes the base outcome of the probabilities corresponding to each outcome. The coefficients thus denote the marginal effect in the probability of engaging in either high intensive or low intensive farming. The model fits well with the estimation because it also allows for the investigation of explanatory variables for the chosen alternative over the other alternatives. Following the work of Torres et al. (2018) and Mwaura and Adong (2016), empirical models for each of the livelihood intensive decision making are specified below.

$$
\frac{P\left(Y_{i}=\text { Semi }- \text { intensive }\right)=}{1+\exp W \delta(1)+\exp W \delta(2)+\exp W \delta(3)}
$$

For the base outcome semi-intensive

$$
P\left(Y_{i}=\text { Intensive }\right)=\frac{1}{1+\exp W \delta(1)+\exp W \delta(2)+\exp W \delta(3)}
$$

$P\left(Y_{i}=\right.$ Low intensive $)=\frac{1}{1+\exp W \delta(1)+\exp W \delta(2)+\exp W \delta(3)}$

Modifying from the work of Mwaura and Adong (2016), the empirical model used in this paper shows socioeconomic factors that influence the livelihood intensive decision making of smallholder farmers and it is expressed in Equation 6.

$Y_{j i}=\delta_{0}+\delta_{1} A g_{i}+\delta_{2} E_{d y r s_{i}}+\delta_{3} F m S z_{i}+$ $\delta_{4} A w L a n G b_{i}+\delta_{5}$ Cult_Int $_{i}+\delta_{6}$ NoAdult $_{i}+$ $\delta_{7}$ Fallowyrs $_{i}+\delta_{8}$ EnoughLan $_{i}+\delta_{9} \mathrm{HHSz}_{i}+$ $\delta_{10}$ Remit $_{i}+\delta_{11}$ EduExp $_{i}+\delta_{12}$ OthHHExp $_{i}+$ $\delta_{13}$ Dist $_{i}+\delta_{14}$ AcqBushLand $_{i}+\delta_{15}$ AcqFalloLand $_{i}+$ $\delta_{16}$ InvestTyp $_{i}+\delta_{17}$ GrabScale $_{i}+\delta_{18}$ GrabYrs $_{i}+$ $\delta_{19}$ LostLand $_{i}+\delta_{20}$ FalloLength $_{i}+e_{i}$

Where: $\delta$ unknown parameter estimates; $W$ explanatory variables and $e$ represents the error term.

The exponent of coefficient in a multinomial logistic regression can be viewed as the probability of choosing alternative regime $\mathrm{j}$ of farm livelihood over the base 
category. The Relative-Risk Ratios (RRR) is the measure of the probability of choosing an alternative over the base outcome.

$R R R=\frac{\operatorname{Pr}\left(Y_{i}=j\right)}{\operatorname{Pr}\left(Y_{i}=\text { Semi-intensive }\right)}=\exp W \delta$

In order to establish the relationship between land acquisitions and livelihood strategy of farm households in the study area, socio-economic characteristics and grabspecific variables were captured. Table 1 shows the definition and measurements of explanatory variables used in the multinomial logit model. The variables are explained as follows.

Age: This variable was measured as a continuous variable, thus the number of years of the farmer. Age of household head has been used in many livelihood studies but the direction of its effects on the dependent variables has been varying and this may depend on many factors. Yizengaw et al. (2014) found age to have no significant influence on choice of livelihood strategy. However, it is expected that older household heads would most likely choose intensive farm livelihood strategy ahead of their younger counterparts because older household heads have better access and control over economic resources.

Years in Education: This variable is measured as the number of years a household head has spent in school. Educated household heads are most likely to be engaged in other formal occupations as found out by Hatlebakk (2012); Gecho et al. (2014) and Rahman and Akter (2014). This study hypothesizes years in schooling to positively influence the decision of a farmer to choose non-intensive farming strategy because household heads with higher education are most likely to engage in formal occupations.

Farm size: This is measured as the total land area under food crop cultivation of a given farmer. Farmers with larger farm sizes are usually wealthier as compared to their counterparts with smaller farm sizes and so there is the likelihood that they would readily choose intensive farming strate gy. Rahut and Micevska (2012) and Gecho et al. (2014) found that farm size had positive influence on farmer's choice of non-farm livelihood; this notwithstanding it is expected that farm size will positively influence a farmers' choice of intensive farming strategy.

Knowledge on other grab lands: This variable is measured as a count variable, thus the number of commercial acquisitions a household head is aware of. The study expects that, the more commercial sites a farmer is aware of, the more his likelihood of choosing intensive farming strategy. This variable is therefore hypothesized to positively influence a farmer's choice of an intensive farming strategy.

Future intention: This is measured as a dummy, thus ' 1 ' if a farmer had a future intention of cultivating part of an acquired land prior to the take over and ' 0 ' if otherwise. A farmer who had a future intention of farming on an acquired land will most likely choose intensive farming strategy. As a result of this, the study expects this variable to have positive influence on intensive farming strategy. Recent Fallow: This is measured as the most recent fallowing engaged by a farmer and it is recorded as number of years. The last time a farmer fallowed can either have a positive or negative influence on the type of farming strategy he chooses. Therefore, it is postulated that recent fallow would have an indeterminate effect on the choice of farming strategy.

Fallow period: This variable is measured as the length of time (years) a farmer allowed fallowing before revisiting the farm land. The fallow period may either have a positive or negative influence on a farmer's choice of farming strategy. This therefore means that the study postulates this variable to be indeterminate.

Adults: This is measured as the number of people in the households who are 18 years and above. The study hypothesizes that a farm household with more adults would most likely be positively influenced to engage in an intensive farming strategy.

Enough land: This is measured as a dummy. Thus ' 1 ' if a farmer concedes to having enough land for cultivation and ' 0 ' if otherwise. It is expected that a farmer who has enough land for cultivation and is therefore not affected by land grabs is expected to engage in a semi-intensive farming system ahead of an intensive farming strategy.

Amount spent on Education: This is measured as the total monthly expenditure spent on wards' education in Ghana Cedis $(\mathrm{GH} \phi)$. The study assumes that the more a farm household spends on education, the less likely they would choose intensive farming strategy. The study therefore postulates this variable to have a negative relationship with the choice of intensive farming strategy.

Other total monthly expenditure: This variable is measured as the amount of money a farm household spends on food, medical bills among others in a month. A farm household that has higher total monthly expenditure is most likely to engage in an intensive farming strategy. Abimbola and Oluwakemi (2013), and Yizengaw et al. (2015) found total household income to have a positive influence on farmers' choice of livelihood strategy. As such the study hypothesizes total monthly expenditure to positively influence the choice of intensive farming strategy.

Remittance: This is a continuous variable measured as the total yearly amount of money received by the household head from relatives and well-wishers outside his community of residence. The influence of remitted amount in this study is indeterminate.

Location: This variable is measured as a dummy, thus ' 1 ' if the farmer is located in KNEM and ' 0 ' if the farmer is located in the Gushegu District. A farmer located in KNEM is assumed to have a positive and strong preference for intensive farming strategy than a farmer in Gushegu District. This is because it is believed that there are larger lands acquired in KNEM than in Gushegu District. The study therefore hypothesizes location to positively influence a farmer's choice of intensive farming strategy.

Land type acquired: This is as andicator variable which was censored as ' 1 ' if acquired land was a bush and ' 0 ' if not; ' 1 ' if acquired land was a fallowed land and ' 0 ' if not; ' 1 ' if acquired land was under cultivated and ' 0 'if not. With cultivated land as reference category, the study expects that farmers within an area where fallowed lands 
were acquired would most likely choose intensive farming.

Grab investment: This variable is measured as dummy, thus ' 1 ' if a grab land is used for the cultivation of arable crop and ' 0 ' if the grab land is used for the establishment of a tree crop plantation. The a priori expectation of this variable on a farmer's choice of farming strategy is indeterminate.

Grab scale: Grab-scale is measured as dummy, thus ' 1 ' for large scale and ' 0 ' for medium scale. The assumption is that larger scale acquisitions have high potential of influencing farmer's farming strategy. This implies that the larger the grab land, the more likely farmers would want to intensify their farming. Therefore, Grab-scale is expected to have a positive influence on the choice of intensive farming strategy.

Grab years: This variable is measured as dummy, thus ' 1 ' if the land had been grabbed for a longer period and ' 0 ' for a shorter period. Farmers who find themselves in communities that have been affected by longer years of grab lands may have a greater incentive to choose intensive farming strategy than their counterparts. The study therefore predicts Grab-years to have positive influence on a farmer's choice of intensive farming strategy.

Grab status: This variable is measured as dummy, thus ' 1 ' if a farmer's land has been lost to land acquisitions (DI) and ' 0 ' if a farmer has not lost land (NI). It is assumed that farmers whose lands have been grabbed, are most likely to choose intensive farming strategy ahead of semiintensive farming strategy. The study therefore hypothesizes victim to have a positive influence on a farmer's choice of intensive farming system.

\section{RESULTS AND DISCUSSION}

\section{Effect of Land Deals on Livelihood Choice Decisions of Farm Households}

The key argument by governments in Sub-Saharan Africa in support of commercial acquisition of land for agriculture is economic development through positive agrarian change. The interface between the 'modern' investors acquiring land for commercial agriculture and rural peasants' improvement is that, the latter is expected to be achieved through the creation of jobs, improvement of incomes and technology transfer that would improve indigenous farming systems. The effect of land grabbing on local farming systems has therefore become a key indicator in assessing the impact of commercial scale agricultural land deals. In this section, the study undertakes an econometric estimation of the effects of land deals on livelihood choice decisions of farm households and this answered the question of finding the relationship that exists between land deals and livelihood decisions, using a multinomial logit regression model. The results for the multinomial logit regression model are shown in Table 2.

From the results, the likelihood-ratio (LR) test of the joint hypothesis shows that the coefficients of all the explanatory variables are significantly different from zero as indicated by the LR Chi-squared $=119.15$ with $\mathrm{p}<0.01$, suggesting that the estimated model is highly significant. The Pseudo $\mathrm{R}^{2}(0.4847)$ means that the model variables were able to predict at least $48.47 \%$ of the probability of farm households' choice of intensive and low intensification farm livelihood regimes ahead of semiintensive. The interpretation of all significant explanatory variables is based on ceteris paribus assumption.

Table 1: Description of variables

\begin{tabular}{lll}
\hline Variable & Definition and measurement & Mean \\
\hline $\mathrm{Ag}$ & Age of household head in years & 46.29 \\
Edyrs & Number of years spent in school & 3.13 \\
FmSz & Farm size of household in acres & 2.74 \\
AwLanGrb & Awareness of land grabbing by household head in the community (1=aware, 0= not & $68.22 \%$ \\
& aware) & $32.45 \%$ \\
Cult_Int & If household head had intention of cultivating part of the area grabbed (1=yes; 0=no) \\
NoAdult & Number of adults in a household & 4.52 \\
Fallowyrs & Most recent year of fallowing farm land & 3.23 \\
EnoughLan & If the household head is satisfied with current size of farm land (1=yes; 0=no) & $28.82 \%$ \\
HHSz & Household size (count) & 11.91 \\
Remit & Remittances (GH $\phi)$ & 235.65 \\
EduExp & Yearly amount spent on wards' education (GH $\phi)$ & 580.50 \\
OthHHExp & Other monthly household expenditure (GH $\phi)$ & 365.04 \\
Dist & District of household (1 for KNE; 0 for Gushiegu) & $46.53 \%$ \\
AcqBushLand & Acquired bush land by investors (1=yes, 0=otherwise) & $22.32 \%$ \\
AcqFalloLand & Acquired fallow land by investors (1=yes, 0=otherwise) & 21.32 \\
LandInvTyp & Agricultural investment that acquired land has been put into (1 for arable crop; 0 for & $35.64 \%$ \\
& tree crop) & $55.94 \%$ \\
GrabScale & Scale of land acquired (1 for large; 0 for medium) & $45.54 \%$ \\
GrabYrs & Years of acquisition (1 for longer; 0 for shorter) & $68.32 \%$ \\
LostLand & If household head has lost land to investors (1=yes; 0=no) & $24.34 \%$ \\
FalloLength & Perception about length of fallow (1=long, 0=short) & \\
\hline
\end{tabular}


Table 2: Multinomial logistic estimation: effects of land deals on livelihood choices

\begin{tabular}{lllll}
\hline & Intensive & \multicolumn{3}{l}{ Low intensive } \\
& RRR & Std. Err. & RRR & Std. Err. \\
\hline Ag & 0.014 & 0.021 & $0.193^{*}$ & 0.112 \\
Edyrs & 0.034 & 0.060 & 0.376 & 0.255 \\
FmSz & $0.043^{* *}$ & 0.019 & -0.103 & 0.123 \\
AwLanGrb & $3.569 * * *$ & 0.841 & 2.088 & 2.655 \\
Cult_Int & $1.272^{*}$ & 0.674 & -13.56 & 146.932 \\
NoAdult & $0.199 * *$ & 0.094 & -0.019 & 0.339 \\
Fallowyrs & 0.237 & 0.200 & $1.556 * *$ & 0.786 \\
EnoughLan & -0.305 & 0.758 & 29.096 & 160.667 \\
HHSz & 0.009 & 0.045 & 0.117 & 0.244 \\
Remit & -0.00016 & 0.0004 & $-0.009 *$ & 0.005 \\
EduExp & $-0.002 * *$ & 0.0008 & $0.019 * *$ & 0.009 \\
OthHHExp & $0.0012 *$ & 0.0007 & $-0.015 *$ & 0.008 \\
Dist & $7.165 * * *$ & 2.199 & 4.959 & 776.201 \\
AqBushLand & -1.115 & 0.764 & 4.787 & 3.758 \\
AqFalloLand & -14.971 & 630.389 & 0.817 & 7.312 \\
LandInvTyp & $3.538 *$ & 1.871 & 2.558 & 244.798 \\
GrabScale & -4.216 & 2.589 & -1.735 & 864.501 \\
GrabYrs & $3.547 * *$ & 1.784 & -9.132 & 206.166 \\
LostLand & -1.158 & 0.763 & 9.703 & 8.434 \\
Fallolength & -0.285 & 0.231 & $-1.495 * *$ & 0.705 \\
Const & -11.270 & 2.757 & -46.283 & 161.339 \\
\hline Pseudo R 20.4847$) ;$ Prob $>$ chi2 $2=0.01 ;$ & Log likelihood $=119.15 ;$ Number of obs $=302$.
\end{tabular}

Farm households' choice of intensive farming regime was positively influenced by farm size. The risk ratio of farm size is $0.043(\mathrm{p}<0.05)$ suggesting that, a marginal increase in farm size would result in a 0.043 probability of a household to choose an intensive farming system over semi-intensive. This contradicts the work of Rahut and Micevska (2012), and Gecho et al. (2014) who found that farm size had positive influence on farmers' choice of non-farm livelihood. This result meets the a priori expectation in the sense that farm households with larger farm sizes are endowed with either social or financial capital and could intensify their faming activities within affected communities in the wake of commercial land deals.

Farm households having knowledge on more than one existing acquisitions within their community had a risk ratio of 3.569 at $1 \%$ significant level and a positive relationship with choosing intensive farming strategy. This means that knowing other acquisitions increases the likelihood of a farm household choosing intensive over semi-intensive regime of farm work. A farm household's knowledge on more than one land acquisition has a direct correlation with reduced community lands. Therefore, respondents intend to make the best use of the available land at their disposal which accounts for their engagement in intensive farming.

Farm households with future intensions of cultivating part of grabbed lands had a positive and significant influence on choosing intensive farming strategy at a risk ratio of 1.272 and a $10 \%$ significance level. This shows that farm households who had future intension are 1.272 times more likely to choose intensive over semi-intensive regime of farm work. This result may be due to the fact that, individual farm households who had the intention of cultivating parts of acquired lands are having the capacity to extend their farming activities and have channelled those resources to intensification.

Total number of adults in a household was positive and significant at $5 \%$ with the choice of intensive farming. Showing that at a 0.199 risk ratio, households with higher number of adults are more likely to choose intensive over semi-intensive regime of farm work. This result meets the a priori expectation because, adults are of the working class and can contribute either labour or capital to intensive farming within the household.

Amount spent on ward's education influences the risk ratios of farm households engaging in the intensive and low intensification regimes of farm work. The risk ratio of intensive was -0.002 showing a negative relationship with education amount but for low intensification the risk ratio was 0.019 . This result indicates that farm households with higher amounts spent on wards education are 0.002 times less likely to engage in intensive farming and are 0.019 more likely to choose low intensification ahead of semiintensive farming. The cost of taking wards through school has direct influence on financial capability of a farm household, hence households with increasing bills on schooling are more likely not to engage in intensive farming. This is because intensive farming requires the purchase of agrochemicals, improved seeds, fertilizer and the use of farm machines. On the other hand, the reverse of this reason is valid in explaining the positive effect of amount spent on wards' education on low intensification.

Also, total monthly expenditure of farm household influences positively the risk ratio of engaging in intensive farming whilst negatively influencing the risk ratio of low intensification. This result indicates that, farm households with higher monthly expenditures are 0.0012 times more likely to engage in intensive farming and are 0.015 less likely to choose low intensification ahead of semi- 
intensive farming. Total monthly expenditure encompasses all expenditures made by the household within a calendar month and reflects a good economic standing of such household. In light of this, it is not surprising that farm households with higher monthly expenditure do engage in intensive farming because they can afford. The result is consistent with the findings of Abimbola and Oluwakemi (2013) and Yizengaw et al. (2014) that total household income has positive influence on farmers' choice of livelihood strategy. This inversely explains the negative effect of higher monthly expenditure on low intensification.

Location of respondents on the other hand shows a positive and significant $(1 \%)$ relationship with the choice of intensive farming at a risk ratio of 7.165. This shows that, given the districts considered in this study, residing in KNEM increases the likelihood of choosing intensive farming ahead of semi-intensive farming, over residing in the Gushiegu District. This may be due to the fact that sizes of land that are grabbed in KNEM are larger in scale as compared to acquisitions in the Gushiegu District. This confirms the study by Yaro (2006) in Kassena Nankana East as farmers engage intensive farming as a result of difficulty in accessing arable land in the area due to land grabbing.

At $10 \%$ significance level, affected communities with acquired lands used for arable crop investments showed positive relationships with the choice of intensive farming. This means that at a risk ratio of 3.538 farm households within such communities are more likely to choose intensive farming ahead of affected communities with tree crop investments. This result may be due to the fact that acquired lands used for arable crop investments are most likely to have irrigation facility which can be taken advantage of by farmers within the catchment area. Therefore, it is not surprising that these farmers engage in intensive farming.

Longer years of grabbing also, showed a positive and significant $(5 \%)$ relationship with the choice of intensive farming. This gives an indication that, at a risk ratio of 3.547 farm households residing in a community which has been affected for longer years are of higher likelihood of choosing intensive farming ahead of communities with shorter years of acquisition. This result also may be due to the fact that longer years of acquisition has contributed to the reduction in farmers' per capita land access, hence the need to adopt intensive farming regime.

Age was positively significant with the choice of low intensification. The risk ratio of age is 0.193 which indicates that at $10 \%$ significant level, farm household with older heads are about 0.193 times more likely to choose low intensification over semi-intensive regime of farm work. Increased age has direct correlation with strength reduction in humans, therefore it is expected that as farmers age increases they are more likely to engage in low intensified farming.

Recent fallow showed a positive relationship with choosing low intensification at $5 \%$ significance level. The risk ratio of recent fallow is 0.237 which indicates that farm household with longer years of recent fallow is about 0.237 times more likely to choose low intensification over semi-intensive regime of farm work. This result is not consistent with the a priori expectation and may be due to the fact that, farmers who have not fallowed their farm lands for a longer period of time are not highly incentivized to farm, hence do not put much investment into farming. Land fallowing has been proven to improve soil fertility, therefore it is expected of motivated farmers to either engage in fallowing or intensify their farming routine.

The results also show a negative relationship between fallow period and the choice of low intensification at $5 \%$ significance level. This means that, with a risk ratio of 1.495 farm households that experiences shorter fallow periods are more likely to choose semi-intensive over low intensification regime of farm work. Farmers with longer fallow period are most likely to sustain soil fertility. This result supports the fact that such farmers do engage in semi-intensive farming ahead of low intensification as they partly complement their farm work with farm inputs and machinery.

Remitted amount received by farm households showed a significance level of $10 \%$ was found to have a negative relationship with the choice of low intensification. This shows that, at a risk ratio of -0.009 farm households that receive lower amounts of remittance are more likely to choose semi-intensive farming ahead of low intensification. The reasoning behind this could be that farm households with low income support from family and well-wishers do rely more on farming activities than their counterparts who receive support.

\section{CONCLUSION}

This study focused on analysing how land deals affect livelihood alternatives for smallholder farm households (intensive, semi-intensive and low intensive methods of farming). The study concludes that, large farm size, household heads' awareness of land grabbing in the community, households having interest of cultivating part of grabbed land, households having more adults, households who have higher total monthly expenditure and households located in KNE municipality have higher probability of using intensive method of farming. Households living in communities where grabbed lands are used for cultivating arable crops and longer number of years of land grabbing prefer intensive to semi-intensive methods of farming. Those who have low propensity to farm under intensive system are households who spend more on education and those who receive higher amount of remittances.

Also, households who have higher probability of engaging in low intensive method of farming as compared to semi-intensive method of farming are older households, households who allow longer period of fallowing and households who spend more on education. Lastly, households are likely to engage in semi-intensive method of farming as compared to low intensive method of farming when they receive high amount of remittances, spend more money on food, medical bills among others, and when they live in communities where grabbed land have been left to fallow for longer period of time.

Land deals must be accompanied by efforts to diversify livelihoods away from land-based systems. This would 
require skills training for rural peasants to enable them take up emerging livelihood opportunities. This is necessary because local peasants who are disposed by commercial land deals have limited options for livelihood. In order to safeguard the interests and livelihood of rural peasants, agricultural investment programmes must make community-investor partnerships a key condition for gaining access to government and donor incentives. Such policies would help reduce elite capture and ensure lands and funds acquired by urban elites translate into investments and livelihood opportunities.

\section{REFERENCES}

ABIMBOLA, A. O. and OLUWAKEMI, O. A. (2013). Livelihood diversification and welfare of rural households in Ondo State, Nigeria. Journal of Development and Agricultural Economics, 5(12), 482-489. DOI: 10.5897/JDAE2013.0497

GECHO, Y., AYELE, G., LEMMA, T., and ALEMU, D. (2014). Rural household livelihood strategies: Options and determinants in the case of Wolaita Zone, Southern Ethiopia. Social Sciences, 3(3), 92-104. DOI: 10.11648/j.ss.20140303.15.

Ghana Statistical Service (GSS) (2012). Population and Housing Census 2010: Summary report of final result.

Ghana Statistical Service (GSS) (2014a). District analytical report; Kassena Nankana East district.

Ghana Statistical Service (GSS) (2014b). District analytical report; Gushiegu district.

GOLDSTEIN, M. and UDRY, C. (2008). The Profits of Power: Land Rights and Agricultural Investment in Ghana Journal of Political Economy, 2008, vol. 116, no. 6. The University of Chicago. DOI: $10.1086 / 595561$.

GREENE, W. H. (2012). Econometric Analysis (Seventh ed.). Boston: Pearson Education. pp. 803-806.

HATLEBAKK, M. (2012). Regional variation in livelihood strategies in Malawi. South African Journal of Economics, 80(1), p. 62-76. DOI: 10.1111/j.18136982.2011.01301.x.

KRANJAC-BERISAVLJEVIC, (2015).
Transformations of traditional landuse systems and their effects on development opportunities and people's livelihoods in Northern Ghana, ICDD Working Papers Paper No. 14

MWAURA, F. M. and ADONG, A. (2016). Determinants of Households' Land Allocation for Crop Production in Uganda, Journal of Sustainable Development, 9 (5): p. 229-246. DOI:10.5539/jsd.v9n5p229

POLASKY, S., COSTELLO, C. and SOLOW, A. (2005). The Economics of Biodiversity. In K-G. Maler, and J. Vincent (Eds.), Chapter 29. Economywide and International Environmental Issues, 3, p. 1517-1560. DOI: 10.1016/S1574-0099(05)03029-9.
PRESSMAN, A., and SUSTAINABLE, N. C. A. T. (2011). Equipment and Tools for Small-Scale Intensive Crop Production: ATTRA.

RAHMAN, S. and AKTER, S. (2014). Determinants of Livelihood Choices: An Empirical Analysis from Rural Bangladesh. Journal of South Asian Development, 9(3), p. 287-308. DOI: $10.1177 \% 2 F 0973174114549101$.

RAHUT, D. B., and MICEVSKA, S. M. (2012). Livelihood diversification strategies in the Himalayas. Australian Journal of Agricultural and Resource Economics, 56(4), p. 558-582. DOI: 10.1111/j.14678489.2012.00596.x.

SCHONEVELD, G. C., GERMAN, L. A. and NUTAKOR, E. (2011). Land-based investments for rural development? A grounded analysis of the local impacts of biofuel feedstock plantations in Ghana. Ecology and Society, 16(4), p. 10. DOI: 10.5751/ES-04424-160410.

SCOONES, I. (1998). Sustainable Rural Livelihoods: A framework for analysis. IDS, Working Paper 72, IDS, Brighton, UK.

SOMORIN, O. A. (2010). Climate impacts, forestdependent rural livelihoods and adaptation strategies in Africa: A review. African Journal of Environmental Science and Technology, 4(13), p. 903-912.

TORRES, B., VASCO, C., GUNTER, S. and KNOKE, T. (2018). Determinants of Agricultural Diversification in a Hotspot Area: Evidence from Colonist and Indigenous Communities in the Sumaco Biosphere Reserve, Ecuadorian Amazon, Sustainability, 2018, 10, 1432; p. 122. DOI: $10.3390 / \mathrm{su} 10051432$

WUNDER, S., ANGELSEN, A. and BELCHER, B. (2014). Forests, livelihoods, and conservation: broadening the empirical base. World Development, 64, p. S1-S11. DOI: $10.1016 /$ j.worlddev.2014.03.007.

YARO, J. A. (2006). Is deagrarianisation real? A study of livelihood activities in rural northern Ghana. The Journal of Modern African Studies, 44(01), p. 125-156.

YARO, J. and TSIKATA D. (2014) Neo-traditionalism, chieftaincy and land grabs in Ghana. Policy Brief, Future Agricultures Consortium. June, 2014.

YIZENGAW, Y. S. and OKOY, E. N. (2014). Determinants of Livelihood Diversification Strategies: The Case of Smallholder Rural Farm Households in Debre Elias Woreda, East Gojjam Zone, Ethiopia, African Journal of Agricultural Research, 10(19), p. 1998-2013. DOI: $10.5897 / A J A R 2014.9192$. 